\title{
Ferric Carboxymaltose in Patients with Heart Failure and Iron Deficiency
}

\author{
Stefan D. Anker, M.D., Ph.D., Josep Comin Colet, M.D., \\ Gerasimos Filippatos, M.D., Ronnie Willenheimer, M.D., \\ Kenneth Dickstein, M.D., Ph.D., Helmut Drexler, M.D.,** \\ Thomas F. Lüscher, M.D., Boris Bart, M.D., Waldemar Banasiak, M.D., Ph.D., \\ Joanna Niegowska, M.D., Bridget-Anne Kirwan, Ph.D., Claudio Mori, M.D., \\ Barbara von Eisenhart Rothe, M.D., Stuart J. Pocock, Ph.D., \\ Philip A. Poole-Wilson, M.D., ** and Piotr Ponikowski, M.D., Ph.D., \\ for the FAIR-HF Trial Investigators ${ }^{\dagger}$
}

A BSTRACT

From the Department of Cardiology, Campus Virchow-Klinikum, Charité Universitätsmedizin, Berlin, and the Center for Clinical and Basic Research, San Raffaele, Rome (S.D.A.); Hospital del Mar and Universitat Autonoma de Barcelona, Barcelona (J.C.C.); Athens University Hospital Attikon, Athens (G.F.); Heart Health Group and Lund University, Malmö, Sweden (R.W.); Stavanger University Hospital, Stavanger, and the University of Bergen, Bergen - both in Norway (K.D.); Medizinische Hochschule Hannover, Hannover, Germany (H.D.); University Hospital Zürich, Zurich (T.F.L.), SOCAR Research, Nyon (B.-A.K.), and Vifor Pharma, Glattbrugg (C.M., B.E.R.) - all in Switzerland; Russian State Medical University, Outpatient Diagnostic Consulting Center 1, Moscow (B.B.); Military Hospital, Wroclaw (W.B., P.P.); Centrum Medyczne, Telmont Centrum Medyczne, Sp. z O.O., Warsaw (J.N.), and Medical University, Wroclaw (P.P.) all in Poland; and London School of Hygiene and Tropical Medicine (S.J.P.) and the National Heart and Lung Institute, Imperial College London (P.A.P.-W.) - both in London. Address reprint requests to Dr. Anker at Applied Cachexia Research, Department of Cardiology, Charité Universitätsmedizin Berlin, Campus Virchow-Klinikum. Augustenburger PI. 1, D-13353 Berlin, Germany, or at s.anker@cachexia.de.

*Deceased.

$\dagger$ Members of the Ferinject Assessment in Patients with Iron Deficiency and Chronic Heart Failure (FAIR-HF) study group are listed in the Appendix.

This article (10.1056/NEJMoa0908355) was published on November 17, 2009, at NEJM. org.

N Engl J Med 2009;361:2436-48.

Copyright () 2009 Massachusetts Medical Society.

\section{BACKGROUND}

Iron deficiency may impair aerobic performance. This study aimed to determine whether treatment with intravenous iron (ferric carboxymaltose) would improve symptoms in patients who had heart failure, reduced left ventricular ejection fraction, and iron deficiency, either with or without anemia.

\section{METHODS}

We enrolled 459 patients with chronic heart failure of New York Heart Association (NYHA) functional class II or III, a left ventricular ejection fraction of $40 \%$ or less (for patients with NYHA class II) or 45\% or less (for NYHA class III), iron deficiency (ferritin level $<100 \mu \mathrm{g}$ per liter or between 100 and $299 \mu \mathrm{g}$ per liter, if the transferrin saturation was $<20 \%$ ), and a hemoglobin level of 95 to $135 \mathrm{~g}$ per liter. Patients were randomly assigned, in a 2:1 ratio, to receive $200 \mathrm{mg}$ of intravenous iron (ferric carboxymaltose) or saline (placebo). The primary end points were the self-reported Patient Global Assessment and NYHA functional class, both at week 24. Secondary end points included the distance walked in 6 minutes and the health-related quality of life.

\section{RESULTS}

Among the patients receiving ferric carboxymaltose, 50\% reported being much or moderately improved, as compared with $28 \%$ of patients receiving placebo, according to the Patient Global Assessment (odds ratio for improvement, 2.51; 95\% confidence interval [CI], 1.75 to 3.61). Among the patients assigned to ferric carboxymaltose, $47 \%$ had an NYHA functional class I or II at week 24 , as compared with $30 \%$ of patients assigned to placebo (odds ratio for improvement by one class, $2.40 ; 95 \% \mathrm{CI}$, 1.55 to 3.71). Results were similar in patients with anemia and those without anemia. Significant improvements were seen with ferric carboxymaltose in the distance on the 6-minute walk test and quality-of-life assessments. The rates of death, adverse events, and serious adverse events were similar in the two study groups.

\section{CONCLUSIONS}

Treatment with intravenous ferric carboxymaltose in patients with chronic heart failure and iron deficiency, with or without anemia, improves symptoms, functional capacity, and quality of life; the side-effect profile is acceptable. (ClinicalTrials.gov number, NCT00520780.) 
ECENT DEVELOPMENTS IN THE MANAGEment of chronic heart failure in patients with an impaired left ventricular ejection fraction have changed the natural history of this clinical syndrome and improved patients' outcomes. ${ }^{1,2}$ However, the normal daily activities of many patients with heart failure remain restricted; they report symptoms of fatigue and dyspnea that adversely affect their quality of life, leading to high morbidity. ${ }^{3,4}$ Therapeutic options to improve functional capacity in patients with heart failure are limited, and novel therapies are needed.

Numerous mechanisms unrelated to hemodynamic dysfunction may underlie impaired exercise tolerance in patients with chronic heart failure. Among them, inadequate oxygen supply and impaired oxygen use by skeletal muscle during exercise contribute to poor clinical status. ${ }^{5,6}$ In addition, anemia may aggravate symptoms in patients with heart failure. ${ }^{7}$ Targeting these abnormalities may confer functional benefits to such patients.

Iron plays a key role in oxygen uptake, transport, and storage, as well as oxidative metabolism in the skeletal muscle; it also is involved in erythropoiesis. ${ }^{8,9}$ Traditionally, iron deficiency has been considered to have clinical consequences only in the presence of anemia. Alternatively, a reduced hemoglobin level can be viewed as the end result of a process beginning with the gradual depletion of iron stores. ${ }^{9,10}$ Iron deficiency in patients with or without anemia attenuates aerobic performance and is accompanied by reports of fatigue and exercise intolerance. ${ }^{11}$ The repletion of iron in patients who have iron deficiency without heart failure improves cognitive, symptomatic, and exercise performance. ${ }^{12,13}$

Recently, it has been recognized that patients with heart failure may be prone to the development of iron deficiency as a consequence of a depletion of iron stores or defective iron absorption and the reduced availability of iron recycled in the reticuloendothelial system. ${ }^{14,15}$ Four small studies showed that the correction of iron deficiency with the use of intravenous iron in patients with chronic heart failure may result in clinical benefits. ${ }^{16-19}$ In one of these studies, ${ }^{17}$ the symptomatic benefit was similar in patients with anemia and those without anemia. We designed our randomized, double-blind study, called the Ferinject Assessment in Patients with Iron Deficiency and Chronic Heart Failure (FAIR-HF) trial, to determine whether the correction of iron deficiency with the use of intravenous iron (ferric carboxymaltose) confers symptomatic benefits in patients with chronic heart failure.

\section{METHODS}

TRIAL DESIGN AND OVERSIGHT

From June 25, 2007, through December 31, 2008, a total of 459 eligible patients were enrolled from 75 sites in 11 countries (Fig. 1 in the Supplementary Appendix, available with the full text of this article at NEJM.org). The study design has been published previously. ${ }^{20}$ The protocol was approved by the institutional review board at each participating center, and the trial was conducted in accordance with the principles of the Declaration of Helsinki, the International Conference on Harmonization Good Clinical Practice guidelines, and local and national regulations. Written informed consent was provided by all patients before any study-related procedures were performed.

The trial was designed, implemented, and overseen by the FAIR-HF Executive Committee, together with representatives of the sponsor, Vifor Pharma (Glattbrugg, Switzerland). ClinStar (Moscow) was responsible for on-site monitoring of sites in Russia and Ukraine. Kendle (Munich, Germany) was responsible for on-site monitoring in other countries, in addition to data collection and data management. SOCAR Research (Nyon, Switzerland) was responsible for data analysis. Analyses were performed independently of the sponsor, according to a predefined plan of statistical analysis. The medical statistics unit at the London School of Hygiene and Tropical Medicine performed the same analyses, separately, with identical results. The manuscript was prepared and submitted for publication by the FAIR-HF Executive Committee. An independent data and safety monitoring board reviewed the safety data on an ongoing basis. The authors had access to the study data and vouch for the accuracy and completeness of the reported data and analyses.

\section{RECRUITMENT AND FOLLOW-UP OF STUDY PATIENTS}

Eligible subjects included ambulatory patients who had chronic heart failure of New York Heart Association (NYHA) class II or III, a left ventricular ejection fraction of $40 \%$ or less (for patients in NYHA class II) or $45 \%$ or less (for patients in NYHA class III), a hemoglobin level at the screening visit between 95 and $135 \mathrm{~g}$ per liter, and iron deficiency. The presence or absence of iron defi- 
ciency was determined on the basis of results received from the central laboratory. Iron deficiency was diagnosed when the serum ferritin level was less than $100 \mu \mathrm{g}$ per liter or was between 100 and $299 \mu \mathrm{g}$ per liter when the transferrin satura- tion was less than $20 \%$. Patients were excluded if they had uncontrolled hypertension, other clinically significant heart disease, inflammation, or clinically significantly impaired liver or renal function.

\begin{tabular}{|c|c|c|}
\hline Variable & $\begin{array}{l}\text { Ferric Carboxymaltose } \\
\qquad(\mathrm{N}=304)\end{array}$ & $\begin{array}{l}\text { Placebo } \\
(\mathrm{N}=155)\end{array}$ \\
\hline Age $-y r$ & $67.8 \pm 10.3$ & $67.4 \pm 11.1$ \\
\hline Female sex — no. (\%) & $159(52.3)$ & $85(54.8)$ \\
\hline White race - no. $(\%) \dagger$ & $303(99.7)$ & $155(100.0)$ \\
\hline \multicolumn{3}{|l|}{ NYHA class - no. (\%) } \\
\hline II & $53(17.4)$ & $29(18.7)$ \\
\hline III & $251(82.6)$ & $126(81.3)$ \\
\hline Left ventricular ejection fraction — \% & $31.9 \pm 5.5$ & $33.0 \pm 6.1$ \\
\hline Body weight — kg & $77.0 \pm 14.2$ & $77.6 \pm 16.3$ \\
\hline Body-mass index & $28.0 \pm 4.8$ & $28.1 \pm 5.1$ \\
\hline \multicolumn{3}{|l|}{ Blood pressure $-\mathrm{mm} \mathrm{Hg}$} \\
\hline Systolic & $126 \pm 15$ & $126 \pm 15$ \\
\hline Diastolic & $77 \pm 9$ & $76 \pm 10$ \\
\hline Pulse - beats/min & $71 \pm 11$ & $72 \pm 12$ \\
\hline 6-Minute walk test distance $-m$ & $274 \pm 105$ & $269 \pm 109$ \\
\hline Ischemic cause of heart failure - no. (\%) & $245(80.6)$ & $123(79.4)$ \\
\hline \multicolumn{3}{|l|}{ Cardiovascular risk factor — no. (\%) } \\
\hline Hypertension, treated with drugs & $243(79.9)$ & $128(82.6)$ \\
\hline Dyslipidemia, treated with drugs & $144(47.4)$ & $70(45.2)$ \\
\hline Diabetes mellitus & $93(30.6)$ & 37 (23.9) \\
\hline Atrial fibrillation & $94(30.9)$ & $44(28.4)$ \\
\hline \multicolumn{3}{|l|}{ Medical history — no. (\%) } \\
\hline Myocardial infarction & $168(55.3)$ & $90(58.1)$ \\
\hline Angina pectoris & $171(56.3)$ & $89(57.4)$ \\
\hline Stroke & $24(7.9)$ & $9(5.8)$ \\
\hline Coronary revascularization & $64(21.1)$ & $31(20.0)$ \\
\hline \multicolumn{3}{|l|}{ Laboratory measurements } \\
\hline Hemoglobin - g/liter & $119 \pm 13$ & $119 \pm 14$ \\
\hline Mean corpuscular volume $-\mu \mathrm{m}^{3}$ & $91.6 \pm 8.1$ & $91.7 \pm 6.7$ \\
\hline Serum ferritin $-\mu \mathrm{g} /$ liter & $52.5 \pm 54.5$ & $60.1 \pm 66.5$ \\
\hline Transferrin saturation — \% & $17.7 \pm 12.6$ & $16.7 \pm 8.4$ \\
\hline C-reactive protein $-\mathrm{mg} /$ liter & $7.46 \pm 5.34$ & $9.12 \pm 5.48$ \\
\hline Sodium - mmol/liter & $141 \pm 3$ & $141 \pm 3$ \\
\hline Potassium $-\mathrm{mmol} / \mathrm{liter}$ & $4.65 \pm 0.61$ & $4.58 \pm 0.52$ \\
\hline Alanine aminotransferase $-U$ /liter & $20.5 \pm 12.3$ & $18.8 \pm 8.1$ \\
\hline Aspartate aminotransferase $-U /$ liter & $23.1 \pm 10.4$ & $22.4 \pm 7.2$ \\
\hline Creatinine $-\mathrm{mg} / \mathrm{dl}$ & $1.2 \pm 0.6$ & $1.2 \pm 0.6$ \\
\hline $\begin{array}{l}\text { Estimated glomerular filtration rate - } \\
\qquad \mathrm{ml} / \mathrm{min} / 1.73 \mathrm{~m}^{2} \text { of body-surface area }\end{array}$ & $63.8 \pm 21.2$ & $64.8 \pm 25.3$ \\
\hline
\end{tabular}




\begin{tabular}{|lcc|}
\hline Table 1. (Continued.) & & \\
\hline & Ferric Carboxymaltose & Placebo \\
(N=304) & (N=155) \\
Concomitant treatment - no. (\%) & & \\
Diuretic & $280(92.1)$ & $140(90.3)$ \\
ACE inhibitor or ARB & $281(92.4)$ & $141(91.0)$ \\
Digitalis glycoside & $46(15.1)$ & $25(16.1)$ \\
Beta-blocker & $262(86.2)$ & $129(83.2)$ \\
Antiplatelet therapy & $189(62.2)$ & $97(62.6)$ \\
Anticoagulant therapy & $67(22.0)$ & $22(14.2)$ \\
Lipid-lowering therapy & $142(46.7)$ & $72(46.5)$ \\
Insulin & $27(8.9)$ & $9(5.8)$ \\
Oral hypoglycemic agent & $49(16.1)$ & $22(14.2)$ \\
\hline
\end{tabular}

* Plus-minus values are means \pm SD. To convert the values for creatinine to micromoles per liter, multiply by 88.4. ACE denotes angiotensin-converting enzyme, ARB angiotensin-receptor blocker, and NYHA New York Heart Association. $\dagger$ Race was self-reported.

$T$ The body-mass index is the weight in kilograms divided by the square of the height in meters.

$\int$ The percent transferrin saturation was calculated as iron (in micromoles per liter) $\div$ transferrin (in grams per liter) $\times 25.1$.

9 The estimated glomerular filtration rate was calculated by the central laboratory according to the Modification of Diet in Renal Disease formula: $186 \times(\text { serum creatinine [in micromoles per liter] } \div 88.4)^{-1.154} \times$ age (in years) ${ }^{-0.203} \times 1.21$ (if patient is black) $\times 0.742$ (if patient is female).

\section{RANDOMIZATION}

Before the iron-correction phase was begun, a clinical history, physical examination, 6-minute walk test results, and 12-lead electrocardiogram were obtained for each patient. We also performed assessments of the health-related quality of life in all patients. Using a central interactive voice-response system, we randomly assigned eligible patients, in a 2:1 ratio, to receive either ferric carboxymaltose (provided by Vifor Pharma) or placebo (normal saline).

\section{STUDY THERAPY AND BLINDING}

The total iron dose required for iron repletion was calculated at baseline, according to Ganzoni's formula ${ }^{21}$ and the mean of the two hemoglobin values obtained during the screening period. The ferric carboxymaltose or saline was administered as an intravenous bolus injection of $4 \mathrm{ml}$ (which is the amount of ferric carboxymaltose in a water solution for injection that is equivalent to $200 \mathrm{mg}$ of iron). The dosing frequency was weekly until iron repletion was achieved (the correction phase) and then every 4 weeks during the maintenance phase, which started at week 8 or week 12, depending on the required iron-repletion dose.

Because ferric carboxymaltose is a dark-brown solution that is easily distinguishable from the saline placebo, study personnel responsible for the preparation and administration of the study drug (including at least one physician) were aware of the group assignments and therefore were not involved in any study assessments. To ensure that patients were unaware of the study drug they were receiving, black syringes were used to administer the study treatment and a curtain (or something similar) was used to shield the injection site from the patient's view.

The central laboratory sent results regarding measures of iron metabolism and hemoglobin only to the study personnel who were aware of the group assignments. These persons were responsible for evaluating for the presence of elevated iron-metabolism measurements or severe anemia and for implementing the following procedures, as defined in the protocol. If the ferritin level exceeded $800 \mu \mathrm{g}$ per liter or was between 500 and $800 \mu \mathrm{g}$ per liter with a transferrin saturation of more than $50 \%$, or if the hemoglobin level was higher than $160 \mathrm{~g}$ per liter, ferric carboxymaltose was discontinued and placebo was given instead. In this case, the ferritin, transferrin saturation, and hemoglobin levels were reassessed. After the ferritin level had dropped to less than $400 \mu \mathrm{g}$ per liter, the transferrin saturation to under $45 \%$, and the hemoglobin level to less than $160 \mathrm{~g}$ per liter, treatment with ferric carboxymaltose could be restarted. If severe anemia (hemo- 
globin level, $\leq 90$ g per liter) developed, the study treatment was permanently discontinued. The follow-up of such patients continued, and further management of anemia was performed at the investigator's discretion.

In addition to the dosing visits, at weeks 4,12 , 24 , and 26 , patients were assessed for efficacy and safety.

\section{PRIMARY AND SECONDARY END POINTS}

The primary end points were the self-reported Patient Global Assessment (Fig. 2 in the Supplementary Appendix) and NYHA functional class (adjusted for the class at baseline) at week 24. Secondary end points included the self-reported Patient Global Assessment and NYHA functional class at week 4 and week 12 , as well as the distance on the 6-minute walk test and the overall score on the Kansas City Cardiomyopathy questionnaire ${ }^{22}$ (on which the overall score ranges from 0 to 100 , with a higher score indicating a better quality of life) and the European Quality of Life-5 Dimensions (EQ-5D) Visual Analog Scale ${ }^{23}$ (on which the score ranges from 0 to 100, with a higher score indicating better health) at weeks 4, 12, and 24 (all adjusted for the baseline data).

Safety end points were serious and nonserious adverse events, hospitalization, and death, as assessed up to week 26. Standardized definitions for the causes of death and hospitalization were developed by members of the FAIR-HF Executive Committee and were supplied to all investigators. ${ }^{20}$

\section{STATISTICAL ANALYSIS}

Data analysis for efficacy was performed according to the intention-to-treat principle for each assigned study group. The planned sample size of 402 patients -268 in the ferric carboxymaltose group and 134 in the placebo group - was calculated on the basis of assumptions that the study would have a statistical power of $90 \%$ (with a twosided alpha of 0.025 ) to detect a mean difference in the NYHA class of 0.50 and in the self-reported Patient Global Assessment ranking of 0.90 (the primary end points) between the two study groups. Assuming that $10 \%$ of patients would not complete the week 24 visit, the planned sample size was increased to 442 . Both primary end points were compared between the two study groups by means of polytomous regression. ${ }^{24}$ For data on the NYHA class, the model was adjusted for the base-
Figure 1 (facing page). Self-Reported Patient Global Assessment and New York Heart Association (NYHA) Functional Class at Week 24, According to Assigned Study Treatment.

Panel A shows the data regarding the self-reported $\mathrm{Pa}$ tient Global Assessment, and Panel B, data regarding the NYHA functional class. The odds ratio for an improvement in the self-reported Patient Global Assessment with ferric carboxymaltose as compared with placebo was 2.51 (95\% confidence interval [Cl], 1.75 to 3.61; $\mathrm{P}<0.001)$. Data on the self-reported Patient Global Assessment were missing for 30 patients known to be alive and not in the hospital at week 24 (18 receiving ferric carboxymaltose and 12 receiving placebo); for these patients, the last available assessment was used as the assessment for week 24. The two patients who were hospitalized at 24 weeks (both receiving ferric carboxymaltose) were assigned an assessment of much worse. The 9 patients who died before week 24 ( 5 who had been receiving ferric carboxymaltose and 4 who had been receiving placebo) were categorized as dead. Panel A does not include 12 patients in the ferric carboxymaltose group and 6 in the placebo group who were known to be alive at week 24 but who had no data on the self-reported $\mathrm{Pa}$ tient Global Assessment at any time during the study. The odds ratio for an improved NYHA class with ferric carboxymaltose as compared with placebo was 2.40 ( $95 \% \mathrm{Cl}, 1.55$ to $3.71 ; \mathrm{P}<0.001)$. Data on the NYHA class were missing for 28 patients known to be alive and not in the hospital at week 24 (16 receiving ferric carboxymaltose and 12 receiving placebo); for these patients, the last available NYHA classification was used as the classification for week 24. The 2 patients who were hospitalized at 24 weeks (both receiving ferric carboxymaltose) were considered to have NYHA class IV. The 9 patients who died before week 24 ( 5 who had been receiving ferric carboxymaltose and 4 who had been receiving placebo) were categorized as being dead (having NYHA class V). The data in Panel B do not include data for 10 patients in the ferric carboxymaltose group and 5 in the placebo group who were known to be alive at week 24 but who had no data on the NYHA functional class at any time during the study. In both panels, percentages may not sum to 100 because of rounding.

line value. The alpha value was adjusted according to the method of Benjamini and Hochberg. ${ }^{25}$

Missing data on the NYHA class and the selfreported Patient Global Assessment were imputed from data collected during the previous follow-up visit, according to the last-observation-carriedforward method, for patients who were known to be alive and not hospitalized at the time of the assessment. For hospitalized patients, a missing NYHA class was assigned as class IV and a missing self-reported Patient Global Assessment was assigned as "much worse." For patients who had died, a missing NYHA class was assigned as 


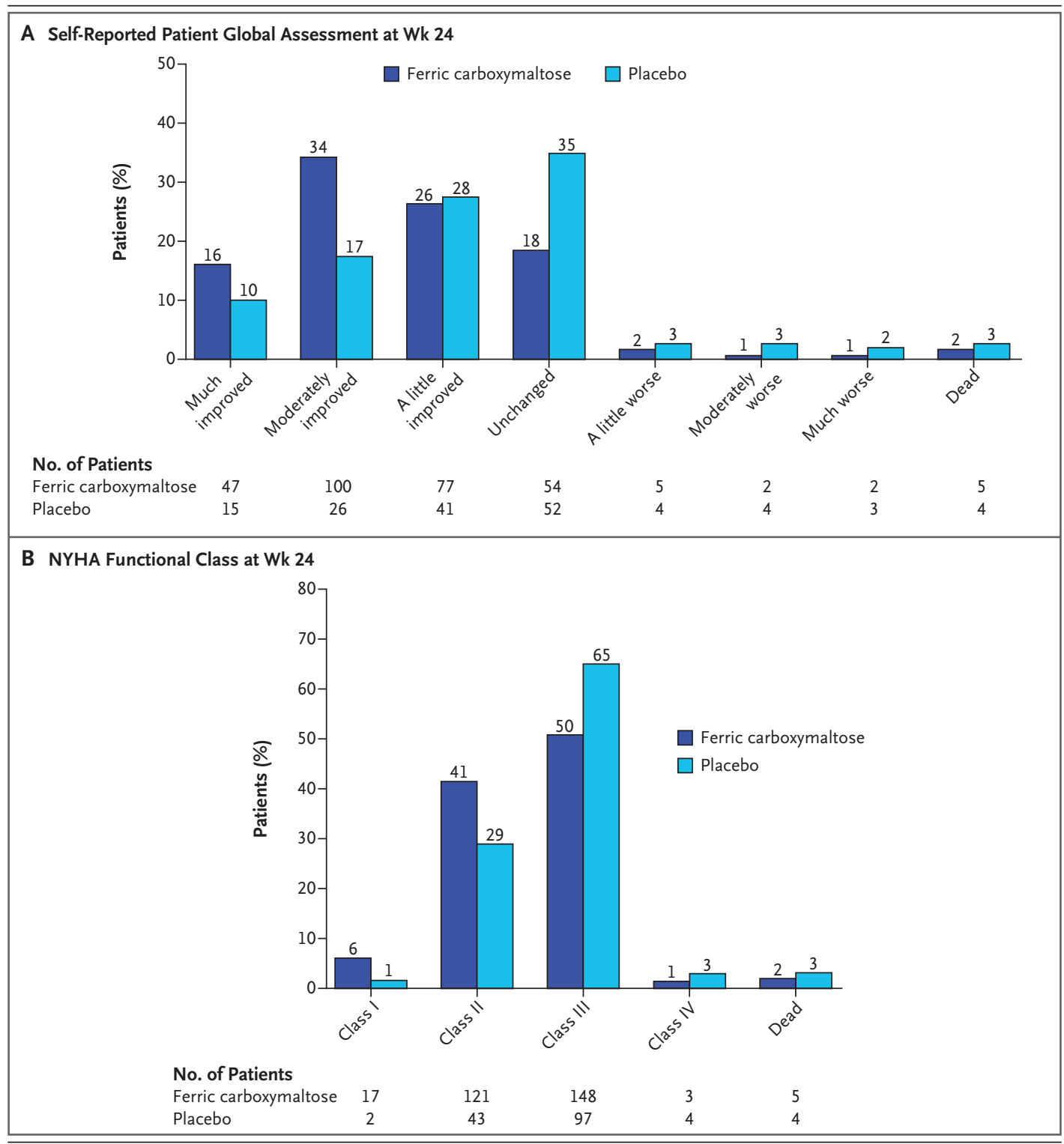

class V and a missing self-reported Patient Global Assessment was assigned as "died." The analysis regarding the primary end points was restricted to data for patients who had at least one valid self-reported Patient Global Assessment or NYHA value, respectively, during the follow-up period.

For the continuous variables, changes from the baseline value and values at weeks 4,12 , and 24 were compared between the ferric carboxymaltose group and the placebo group by comparing the means within each of the two study groups at each visit with the use of a model for repeated measures adjusted for baseline values. For categorical end points, differences in the distribution for each of the two study groups were tested by means of ordered polytomous regression. Tests

for interaction were performed as part of the subgroup analysis regarding the primary end points by adding an interaction term to the ordered polytomous regression model. Cox proportional-hazards regression models were used to estimate the hazard ratios for safety outcomes on the basis of the treatment received. Event rates are reported per person-year at risk. All analyses were conducted with the use of SAS software, version 9.1 (SAS Institute).

RESULTS

\section{CHARACTERISTICS OF THE STUDY PATIENTS}

The clinical characteristics of 459 patients are presented in Table 1. A total of 304 patients were ran- 
domly assigned to receive ferric carboxymaltose and 155 to receive placebo. The two groups were similar with respect to the baseline clinical and laboratory characteristics and the use of cardiovascular medications at the time of enrollment.

\section{FOLLOW-UP}

Of the 304 patients assigned to receive ferric carboxymaltose, $26(8.6 \%)$ did not complete the 24 weeks of follow-up; of these 26, 5 had died and 21 had withdrawn (Fig. 1 in the Supplementary Appendix). Of the 155 patients assigned to receive placebo, 20 (12.9\%) did not complete the 24 weeks of follow-up; of these 20, 4 had died and 16 had withdrawn.

\section{PRIMARY END POINTS}

The self-reported Patient Global Assessment at week 24 was improved in the ferric carboxymaltose group, with $50 \%$ of patients reporting that they were much or moderately improved, as compared with $28 \%$ of patients in the placebo group (odds ratio for being in a better rank, 2.51; 95\% confidence interval [CI], 1.75 to 3.61; $\mathrm{P}<0.001$ ) (Fig. 1A). Similarly, the NYHA functional class at week 24 , after adjustment for the baseline value was improved in the ferric carboxymaltose group, with $47 \%$ having an NYHA functional class I or II, as compared with $30 \%$ in the placebo group (odds ratio for improvement by one class, 2.40; $95 \% \mathrm{CI}$, 1.55 to 3.71; $\mathrm{P}<0.001$ ) (Fig. 1B).

\section{SECONDARY END POINTS}

The use of ferric carboxymaltose, as compared with placebo, significantly improved the self-reported Patient Global Assessment and NYHA class at weeks 4 and 12 ( $\mathrm{P}<0.001$ for all comparisons) (Fig. $2 \mathrm{~A}$ and $2 \mathrm{~B}$, and Fig. 3 and 4 in the Supplementary Appendix). Significant improvements were also seen in the distance on the 6-minute walk test and in the quality of life, as evaluated by the EQ-5D visual assessment score and the overall Kansas City Cardiomyopathy score, at weeks 4, 12, and 24 ( $\mathrm{P}<0.001$ for all comparisons) (Fig. 2C, 2D, and 2E).

\section{SUBGROUP ANALYSES}

A consistent benefit regarding the two primary end points was observed in all prespecified subgroups (Fig. 3). The treatment effect was similar in patients with anemia and in those without anemia (prospectively defined as a hemoglobin level $\leq 120 \mathrm{~g}$ per liter at baseline).
Figure 2 (facing page). Main Secondary Outcomes during the Study, According to Assigned Study Treatment.

Shown are data across the study period for the selfreported Patient Global Assessment (Panel A), the New York Heart Association (NYHA) functional class (Panel B), change in distance on the 6-minute walk test (Panel C), the change in the score on the European Quality of Life-5 Dimensions (EQ-5D) Visual Analog Scale (on which the score ranges from 0 to 100, with higher scores indicating better health) (Panel D), and the change in the overall score on the Kansas City Cardiomyopathy questionnaire (on which the overall score ranges from 0 to 100 , with a higher score indicating a better quality of life) (Panel E). The data in Panels $A$ and $B$ are odds ratios, for the ferric carboxymaltose (FCM) group as compared with the placebo group and shown on a $\log _{2}$ scale, of being in a better assessment category (Panel A) or NYHA functional class (Panel B) In both panels, for data on the self-reported Patient Global Assessment that were missing for patients known to be alive and not in the hospital at each time point, the last available assessment was used. Patients who were hospitalized at each time point were given an assessment of much worse (in Panel A) or an NYHA class of IV (in Panel B). Patients who died before week 24 were categorized as dead (in Panel B, corresponding to NYHA class $\mathrm{V}$ ). Data were not included for patients who were known to be alive at the time point but had no previous data. For Panel A, the odds ratios at week 4 and week 12 are 3.44 (95\% confidence interval [Cl], 2.34 to 5.07$)$ and $3.19(95 \% \mathrm{Cl}, 2.20$ to 4.63). In Panel B, the odds ratios at week 4 and week 12 are $3.96(95 \% \mathrm{Cl}, 1.98$ to 7.93$)$ and $3.42(95 \% \mathrm{Cl}$, 2.04 to 5.72). Panels $C, D$, and $E$ show the mean ( \pm SE) changes in the variable at weeks 4,12 , and 24 . In those panels, the $P$ values are for the comparison between the two study groups, and the I bars denote the standard error.

\section{SAFETY AND BIOCHEMICAL ANALYSES}

Survival status was available for all patients through at least week 24. The rates of death, hospitalization, and serious and nonserious adverse events reported by the investigators were similar in the two study groups (Table 2). There was a trend toward a lower rate of first hospitalization for any cardiovascular reason among patients receiving ferric carboxymaltose as compared with those receiving placebo (hazard ratio, 0.53 ; $95 \% \mathrm{CI}, 0.25$ to $1.09 ; \mathrm{P}=0.08$ ). The hazard ratio for death or first hospitalization for any cardiovascular reason among patients who received ferric carboxymaltose as compared with those who received placebo was 0.61 ( $95 \%$ CI, 0.32 to $1.18 ; \mathrm{P}=0.14$ ).

Data on serious and nonserious adverse events are also shown in Table 2, and in Table 1 in the Supplementary Appendix. The study treatment 


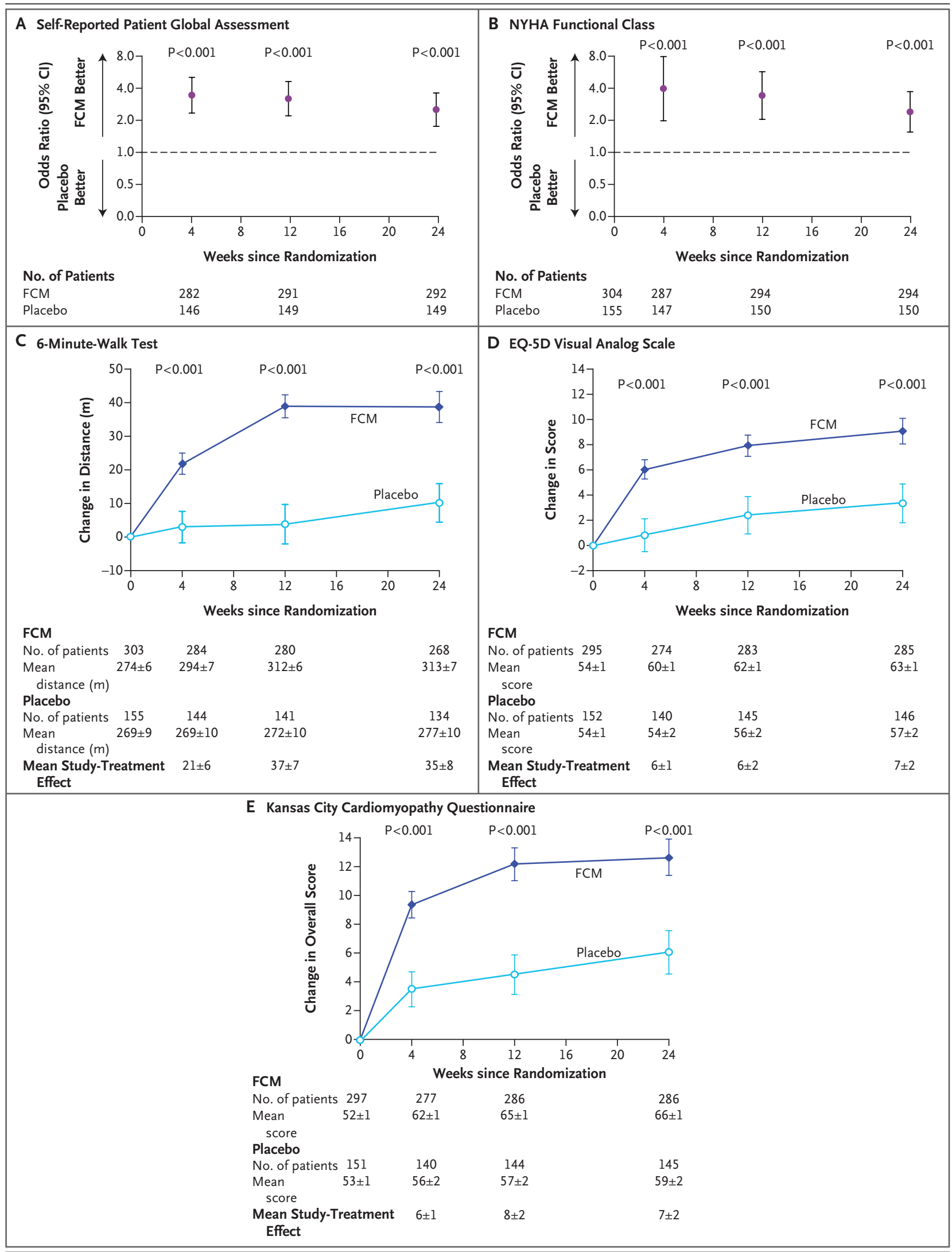

N ENGLJ MED 361;25 NEJM.ORG DECEMBER 17, 2009

The New England Journal of Medicine 


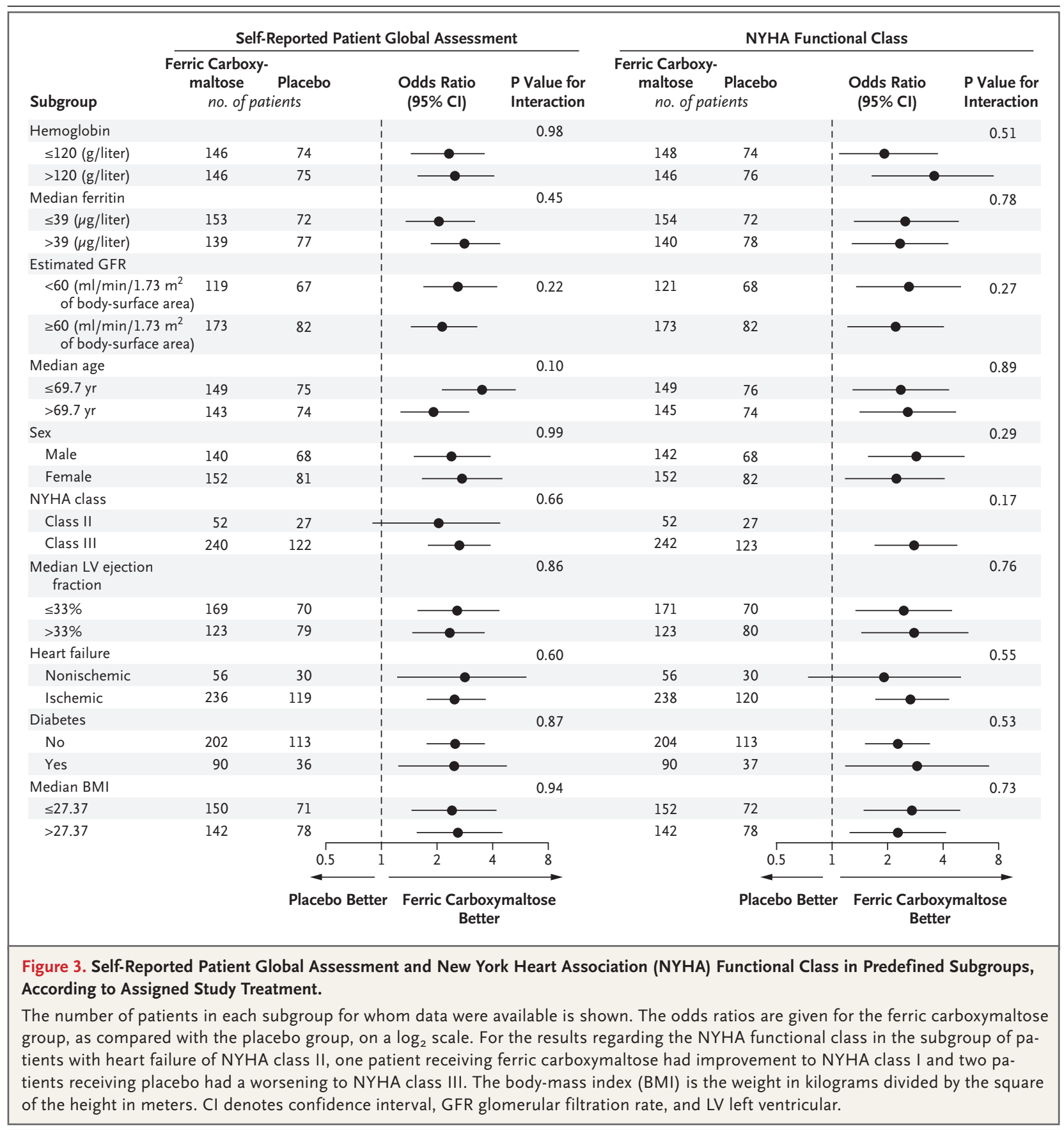

was stopped prematurely in 16 (5.3\%) of the 304 patients assigned to receive ferric carboxymaltose and in 14 (9.0\%) of the 155 patients assigned to receive placebo. No severe allergic reactions related to the study treatment were reported. Of the patients treated with ferric carboxymaltose, injection-site discoloration was reported for four patients and injection-site pain for two patients.
Laboratory values for ferritin, transferrin saturation, and hemoglobin at week 24 were significantly different between the two study groups ( $\mathrm{P}<0.001$ for all comparisons) (Table 3). The mean $( \pm S E)$ difference in the ferritin level (adjusted for baseline) between patients receiving ferric carboxymaltose and those receiving placebo was $243 \pm 17 \mu$ g per liter at week 4, 188 $\pm 15 \mu$ g per liter 


\begin{tabular}{|c|c|c|c|c|c|}
\hline \multirow[t]{2}{*}{ End Point or Event } & \multicolumn{2}{|c|}{$\begin{array}{l}\text { Ferric Carboxymaltose } \\
\qquad(\mathrm{N}=305)\end{array}$} & \multicolumn{2}{|c|}{$\begin{array}{l}\text { Placebo } \\
(\mathrm{N}=154)\end{array}$} & \multirow[t]{2}{*}{ P Value } \\
\hline & $\begin{array}{l}\text { No. of End } \\
\text { Points or } \\
\text { Serious } \\
\text { Adverse/ } \\
\text { Any Adverse } \\
\text { Events }\end{array}$ & $\begin{array}{l}\text { No. of Patients } \\
\text { with End Point } \\
\text { or Event } \\
\text { (incidence/ } \\
100 \text { patient-yr } \\
\text { at risk) }\end{array}$ & $\begin{array}{l}\text { No. of End } \\
\text { Points or } \\
\text { Serious } \\
\text { Adverse/ } \\
\text { Any Adverse } \\
\text { Events }\end{array}$ & $\begin{array}{l}\text { No. of Patients } \\
\text { with End Point } \\
\text { or Event } \\
\text { (incidence/ } \\
100 \text { patient-yr } \\
\text { at risk) }\end{array}$ & \\
\hline \multicolumn{6}{|l|}{ Safety end point } \\
\hline Death & 5 & $5(3.4)$ & 4 & $4(5.5)$ & 0.47 \\
\hline Death due to cardiovascular causes & 4 & $4(2.7)$ & 4 & $4(5.5)$ & 0.31 \\
\hline Death due to worsening heart failure & 0 & 0 & 3 & $3(4.1)$ & \\
\hline First hospitalization & 28 & $25(17.7)$ & 22 & $17(24.8)$ & 0.30 \\
\hline Hospitalization for any cardiovascular cause & 16 & $15(10.4)$ & 18 & $14(20.0)$ & 0.08 \\
\hline Hospitalization for worsening heart failure & 7 & $6(4.1)$ & 9 & $7(9.7)$ & 0.11 \\
\hline Any hospitalization or death & 33 & $30(21.2)$ & 26 & $19(27.7)$ & 0.38 \\
\hline Hospitalization for any cardiovascular cause or death & 21 & 20 (13.9) & 22 & $16(22.9)$ & 0.14 \\
\hline First hospitalization for worsening heart failure or death & 12 & $11(7.5)$ & 13 & $10(13.9)$ & 0.15 \\
\hline \multicolumn{6}{|l|}{ Investigator-reported adverse event } \\
\hline Cardiac disorder & $12 / 46$ & $38(27.6)$ & $23 / 49$ & $33(50.2)$ & 0.01 \\
\hline Gastrointestinal disorder & $2 / 29$ & $24(16.9)$ & $2 / 7$ & $5(6.9)$ & 0.06 \\
\hline General disorder or injection-site condition & $4 / 28$ & $23(16.2)$ & $1 / 6$ & $6(8.3)$ & 0.14 \\
\hline Injection-site pain or discoloration & $0 / 6$ & $6(4.1)$ & $0 / 0$ & 0 & \\
\hline Infection or infestation & $2 / 56$ & $50(37.0)$ & $0 / 32$ & $24(35.8)$ & 0.97 \\
\hline Abnormal laboratory test, vital sign, or physical finding & $0 / 63$ & $32(23.0)$ & $0 / 10$ & $10(14.0)$ & 0.17 \\
\hline Nervous system disorder & $3 / 29$ & $22(15.6)$ & $3 / 20$ & $14(20.3)$ & 0.44 \\
\hline Respiratory, thoracic, or mediastinal disorder & $0 / 9$ & $9(6.2)$ & $3 / 13$ & $10(14.2)$ & 0.06 \\
\hline Vascular disorder & $3 / 24$ & $20(14.0)$ & $1 / 13$ & $11(15.7)$ & 0.80 \\
\hline
\end{tabular}

* Adverse events are classified on the basis of the system organ classes of the Medical Dictionary for Regulatory Activities. Events that were reported in more than $4 \%$ of all the study patients are listed here. One patient who had been randomly assigned to the placebo group received ferric carboxymaltose.

at week 12, and $246 \pm 20 \mu \mathrm{g}$ per liter at week 24 ( $\mathrm{P}<0.001$ for all comparisons). The corresponding mean differences in the hemoglobin level were $6.6 \pm 1.1,10.6 \pm 1.3$, and $5.9 \pm 1.5$ g per liter, respectively ( $\mathrm{P}<0.001$ for all comparisons), and the corresponding mean differences in the mean corpuscular volume of erythrocytes were $1.5 \pm 0.4,2.4 \pm 0.5$, and $2.7 \pm 0.7 \mu \mathrm{m}^{3}$, respectively (all $\mathrm{P}<0.001$ ). The mean difference in the hemoglobin level at week 24 (adjusted for baseline) between the ferric carboxymaltose group and the placebo group was not significant among patients who did not have anemia at baseline $(2.4 \pm 2.0 \mathrm{~g}$ per liter, $\mathrm{P}=0.21)$ but was significant among patients who had anemia at baseline $(9.1 \pm 2.2 \mathrm{~g}$ per liter, $\mathrm{P}<0.001)$. The mean difference in estimated glomerular filtration rate (adjusted for baseline) between patients receiving ferric carboxymaltose and those receiving placebo was $3.8 \pm 1.8 \mathrm{ml}$ per minute $(\mathrm{P}=0.03)$. There were no significant differences between the two study groups with respect to adverse-event reporting based on chemical values and other hematologic laboratory test results.

\section{DISCUSSION}

Treatment with ferric carboxymaltose for 24 weeks in patients who had chronic heart failure and iron deficiency with or without anemia improved symptoms, functional capacity, and the quality of life. 


\begin{tabular}{|c|c|c|c|}
\hline Variable & $\begin{array}{l}\text { Ferric Carboxymaltose } \\
\qquad(\mathrm{N}=\mathbf{3 0 5})\end{array}$ & $\begin{array}{l}\text { Placebo } \\
(\mathrm{N}=154)\end{array}$ & P Value \\
\hline \multicolumn{4}{|l|}{ All patients } \\
\hline Ferritin $(\mu \mathrm{g} /$ liter $)$ & $312 \pm 13$ & $74 \pm 8$ & $<0.001$ \\
\hline Transferrin saturation (\%) $\dagger$ & $29 \pm 1$ & $19 \pm 1$ & $<0.001$ \\
\hline Hemoglobin (g/liter) & $130 \pm 1$ & $125 \pm 1$ & $<0.001$ \\
\hline Mean corpuscular volume $\left(\mu \mathrm{m}^{3}\right)$ & $97 \pm 0$ & $94 \pm 1$ & $<0.001$ \\
\hline \multicolumn{4}{|c|}{ Patients with anemia (hemoglobin $\leq 120 \mathrm{~g} /$ liter) } \\
\hline Ferritin $(\mu \mathrm{g} /$ liter $)$ & $275 \pm 18$ & $68 \pm 11$ & $<0.001$ \\
\hline Transferrin saturation (\%) $†$ & $29 \pm 1$ & $17 \pm 1$ & $<0.001$ \\
\hline Hemoglobin (g/liter) & $127 \pm 1$ & $118 \pm 2$ & $<0.001$ \\
\hline Mean corpuscular volume $\left(\mu \mathrm{m}^{3}\right)$ & $98 \pm 1$ & $93 \pm 1$ & $<0.001$ \\
\hline \multicolumn{4}{|c|}{ Patients without anemia (hemoglobin $>120 \mathrm{~g} /$ liter) } \\
\hline Ferritin $(\mu \mathrm{g} /$ liter $)$ & $349 \pm 19$ & $80 \pm 11$ & $<0.001$ \\
\hline Transferrin saturation (\%) $\dagger$ & $30 \pm 1$ & $22 \pm 1$ & $<0.001$ \\
\hline Hemoglobin (g/liter) & $133 \pm 1$ & $132 \pm 1$ & 0.21 \\
\hline Mean corpuscular volume $\left(\mu \mathrm{m}^{3}\right)$ & $96 \pm 1$ & $95 \pm 1$ & 0.91 \\
\hline
\end{tabular}

* Plus-minus values are means $\pm \mathrm{SE}$. The $\mathrm{P}$ value is for the mean treatment effect, adjusted for the baseline value. One patient who had been randomly assigned to the placebo group received ferric carboxymaltose.

$\uparrow$ The percent transferrin saturation was calculated as iron (in micromoles per liter) $\div$ transferrin (in grams per liter) $\times 25.1$.

Our study also showed that treatment with ferric carboxymaltose was not associated with an unacceptable side-effect or adverse-event profile.

Our study showed improvement with ferric carboxymaltose in the two primary end points: the self-reported Patient Global Assessment and the NYHA class at 24 weeks. The benefit was evident after 4 weeks and was maintained throughout the study period. These results were consistent across all prespecified subgroups and were confirmed by the observed improvements in distance on the 6-minute walk test distance and in scores on the health-related quality-of-life questionnaires.

Our patient population was identified on the basis of laboratory biomarkers, ferritin, transferrin saturation, and hemoglobin. These variables were also used to calculate the iron-repletion dose and to guide decisions about continuation or interruption of ferric carboxymaltose. In that sense, the trial is a double-blind treatment trial that used guidance based on blood-sample data for studytreatment initiation and monitoring. The study results suggest that in the assessment of ambulatory patients with symptomatic heart failure and systolic dysfunction, laboratory investigations to detect iron deficiency may be useful in routine practice to decide whether symptom management, by means of treatment with intravenous iron, is indicated.

The dose needed to correct iron deficiency was calculated according to Ganzoni's formula ${ }^{21}$ and was provided over a period between 3 and 7 weeks (a median of six injections) during the correction phase. We required that iron was given in doses of $200 \mathrm{mg}$ per application and that the dosing frequency was weekly during the correction phase and monthly during the maintenance phase. The results of our study are applicable only to this dosing regimen. Treatment approaches involving higher doses and higher ferritin thresholds for the interruption of therapy are untested in patients with heart failure.

The treatment with ferric carboxymaltose was beneficial to both patients with anemia and those without anemia. This suggests that iron deficiency is a valid independent therapeutic target. Iron metabolism in patients with chronic illness merits a more detailed investigation to unravel the reasons why the correction of iron deficiency can result in symptomatic improvements even in the absence of a change in hemoglobin. Our results are consistent with those from four small studies that 
were performed with the use of a different preparation of intravenous iron. ${ }^{16-19}$ One of these studies ${ }^{15}$ recruited a subgroup of patients without anemia who had even higher hemoglobin levels than our patients (i.e., 125 to 145 g per liter). We do not know the limit of hemoglobin up to which iron deficiency is pathophysiologically important. On the basis of our current findings, we cannot recommend treatment with ferric carboxymaltose for patients who have chronic heart failure, iron deficiency, and a hemoglobin level above $135 \mathrm{~g}$ per liter, but such therapy is an area of interest for future research.

In conclusion, in stable, symptomatic, ambulatory patients with chronic heart failure, an impaired left ventricular ejection fraction, and iron deficiency, treatment with ferric carboxymaltose over a 24-week period improves symptoms, physical performance, and the quality of life and has acceptable side-effect and adverse-event profiles.
The benefit was seen in patients with anemia and in those without anemia.

Sponsored by Vifor Pharma.

Dr. Anker reports receiving lecture fees from Roche Pharma and Teva; Drs. Anker, Comin Colet, Filippatos, Willenheimer, Dickstein, Lüscher, and Ponikowski, fees from Vifor Pharma as members of the FAIR-HF Executive Committee; Drs. Anker, Willenheimer, and Ponikowski, lecture and consulting fees from Vifor Pharma and Amgen; and Dr. Willenheimer, lecture fees from Merck and Servier; Dr. Kirwan reports being an employee of SOCAR Research, which received fees from Vifor Pharma; Drs. Mori and von Eisenhart Rothe report being employees of Vifor Pharma and owning stock in Galenica; and Dr. Pocock reports receiving fees from Vifor Pharma as the FAIR-HF consultant statistician. Financial and other disclosures provided by the authors are available with the full text of this article at NEJM.org.

We thank the study coordinators, nurses, and staff at the investigative sites and especially all of the patients involved in the FAIR-HF trial; Elena Malyshko (ClinStar) and Miriana Wennekes (Kendle) and their study teams for study monitoring and management; Sophie De Brouwer (SOCAR Research) and Tim Clayton (London School of Hygiene and Tropical Medicine) for the statistical analysis; and Nicola Waddingham and Giedrius Gaudesius (Vifor Pharma) for overall study coordination. We dedicate this article to the memory of our colleagues Philip A. Poole-Wilson and Helmut Drexler, who did not live to see the results of this trial.

APPENDIX

The members of the FAIR-HF study group are as follows: Executive Committee: S.D. Anker (chair), P. Ponikowski (cochair), K. Dickstein, G.S. Filippatos, T.F. Lüscher, R. Willenheimer, J. Comin Colet, H. Drexler (deceased), P.A. Poole-Wilson (deceased); and Data Safety and Monitoring Board: R.P. Wüthrich (chair), J. Lubsen. The FAIR-HF site investigators and institutions were as follows (with numbers of recruited patients per country in parentheses): Argentina (6): J.H. Altamirano, Instituto de Investigaciones Cardiológicas Prof. Dr. Alberto C. Taquini, Buenos Aires; S.V. Rodriguez, Instituto de Diagnóstico Cardiovascular La Plata, Buenos Aires; Czech Republic (17): J. Špinar, Fakultní Nemocnice Brno, Brno; J. Povolný, Oblastní Nemocnice Kladno, Kladno; J. Bělohlávek, Vseobecna Fakultní Nemocnice, Prague; Z. Palúch, Fakultní Thomayerova Nemocnice, Prague; J. Horák, Fakultní Nemocnice Kralovske Vinohrady, Prague; Germany (11): S. Anker, Charité Berlin, Campus Virchow-Klinikum, Berlin; D. Wolf, CardioSec Clinical Research, Erfurt; M. Natour, Praxis Dr. M. Natour und M. Durak, Heidelberg; Greece (11): A. Manolis, General Hospital of Voula Asklipion, Athens; J. Nanas, Alexandras General Hospital, Athens; D.T. Kremastinos, University Hospital of Athens Attikon, Athens; D. Alexopoulos, University Hospital of Patras, Patras; Italy (11): M. Volterrani, Istituto di Ricovero e Cura a Carattere Scientifico San Raffaele Pisana, Rome; G. Vescovo, Unità Locale Socio Sanitaria 6 Ospedale San Bortolo, Vicenza; Norway (2): K. Dickstein, Stavanger Helseforskning, Stavanger; Poland (60): M. Mysliwiec, Wojewodzki Szpital Specjlaistyczny im K. Dluskiego, Białystok; M. Ogorek, Samodzielny Szpital Wojewodzki im M. Kopernika, Piotrkow Trybunalski; P. Staneta, Niepubliczny zakład Opieki Zdrowotnej Specjalistyczna Przychodnia Lekarska, Medikard, Plock; J. Niegowska, Centrum Medyczne, Telmont Centrum Medyczne, Sp. z O.O., Warsaw; M. Dłuzniewski, Wojewódzki Szpital Bródnowski, Warsaw; P. Ponikowski, 4 Wojskowy Szpital Kliniczny z Polikliniką, Wroclaw; L. Polonski, Slaskie Centrum Chorob Serca, Zabrze; Romania (16): M. Radoi, Spitalul Clinic de Urgenta Brasov, Brasov; C.E. Macarie, Institutul de Boli Cardiovasculare Prof. Dr. C.C. Iliescu, Bucharest; G.A. Dan, Spitalul Clinic Colentina, Bucharest; P.I. Kikeli, Societatea Civila Medicala Procardia Medical, Targu Mures; Russia (200): E.S. Pasechnik, State Institution of Healthcare Kaluzhskaya Regional Hospital, Kaluga; A.A. Eremenko, Russian Scientific Center of Surgery of the Russian Academy of Medical Sciences, Moscow; A.A. Gorbachenkov, Central Clinical Hospital of Civil Aviation of the Ministry of Transport of the Russian Federation, Moscow; A.E. Bragina, City Clinical Hospital 61, Moscow; A.Y. Ivleva, Outpatient Clinic 3 of President of the Russian Federation Administration, Moscow; B.Y. Bart, Russian State Medical University, Outpatient Diagnostic Consulting Center 1, Moscow; G.P. Arutyunov, City Clinical Hospital 4, Moscow; R.A. Khokhlov, Voronezhsky Regional Hospital 1, Voronezh; S.N. Tereschenko, Moscow State Medicine and Dentistry University of the Federal Agency for Health Care and Social Development, Moscow; V.A. Lusov, Russian State Medical University, Moscow; V.N. Ardashev, Main Military Clinical Hospital, Moscow; V.Y. Mareev, Cardiology Research Complex, Moscow; Z.D. Kobalava, Russian State People Friendship University, Moscow; O.P. Alexeeva, City Hospital 33, Nizhny Novgorod; V.E. Oleynikov, State Institution of Healthcare Regional Clinical Hospital, Penza; N.A. Koziolova, Permsky Regional Hospital of War Veterans, Perm; D.V. Duplyakov, State Institute of Healthcare Regional Cardiology Dispensary of Samara, Samara; A.A. Petrov, Leningrad Regional Clinical Hospital, St. Petersburg; D.U. Butko, International Clinic and Hospital Medem, St. Petersburg; M.Y. Sitnikova, Research Institute of Cardiology, St. Petersburg; O.A. Berkovich, St. Petersburg State Medical University, St. Petersburg; S.A. Boldueva, St. Petersburg State Medical Academy, St. Petersburg; S.R. Minkin, City Consultive-Diagnostical Center 1, St. Petersburg; V.A. Kostenko, St. Petersburg Scientific Research Institute for Emergency, St. Petersburg; Y.G. Shvarts, Saratov State Medical University of Roszdrav, Saratov; Y.B. Karpov, Voronezhsky Hospital of Emergency 1, Voronezh; S.V. Nedogoda, Regional Clinical Hospital of Volgograd, Volgograd; Spain (22): J. Bruguera, Hospital del Mar, Barcelona; J. González Costelló, Hospital Universitari de Bellvitge, Barcelona; M. Martínez Sellés, Hospital General Universitario Gregorio Marañon, Madrid; J. Quiles Granado, Hospital Universitario San Juan de Alicante, San Juan de Alicante; Ukraine (103): O.A. Koval, Dnipropetrovsk State Medical Academy, Hospital Therapy 2, Dnipropetrovsk; G.A. Ignatenko, Donetsk State Medical University, Donetsk; I.G. Kraiz, Central Clinical Hospital of Ukrzaliznitsya, Kharkiv; O.V. Prohorov, City Clinical Hospital 27, Kharkiv; V.I. Tseluyko, Kharkiv Medical Academy of Postgraduate Education, Kharkiv; O.M. Parkhomenko, National Scientific Center Institute of Cardiology Academician Strazheska, Kiev; K.M. Amosova, National Medical University, Kiev; L.V. Rudenko, Clinical Hospital of Emergency Medical Service, Kiev; O.M. Gyrina, National 
Medical University, Kiev; V.Y. Lishnevska, Institute of Gerontology of the Academy of Medical Science of Ukraine, Kiev; S.S. Pavlyk, Regional State Clinical Treatment-and-Diagnostic Cardiology Center, Lviv; I.P. Kovalsky, City Hospital 1 of Mykolayiv, Mykolayiv; G.S. Popik, Odessa State Medical University, Odessa; Z.Y. Telyatnikova, Municipal Institution, City Policlinic 20, Odessa; I.V. Chopey, Uzhgorod National University, Uzhgorod; V.A. Vizir, Zaporizhzhya State Medical University, Zaporizhzhya.

\section{REFERENCES}

1. Hunt SA, Abraham WT, Chin MH, et al. 2009 Focused update incorporated into the ACC/AHA 2005 Guidelines for the Diagnosis and Management of Heart Failure in Adults: a report of the American College of Cardiology Foundation/ American Heart Association Task Force on Practice Guidelines developed in collaboration with the International Society for Heart and Lung Transplantation. J Am Coll Cardiol 2009;53(15):e1-e90.

2. Dickstein K, Cohen-Solal A, Filippatos $\mathrm{G}$, et al. ESC guidelines for the diagnosis and treatment of acute and chronic heart failure 2008: the Task Force for the diagnosis and treatment of acute and chronic heart failure 2008 of the European Society of Cardiology: developed in collaboration with the Heart Failure Association of the ESC (HFA) and endorsed by the European Society of Intensive Care Medicine (ESICM). Eur J Heart Fail 2008;10. 933-89.

3. Jessup M, Brozena S. Heart failure. N Engl J Med 2003;348:2007-18.

4. Roger VL, Weston SA, Redfield MM, et al. Trends in heart failure incidence and survival in a community-based population. JAMA 2004;292:344-50.

5. Clark AL, Poole-Wilson PA, Coats AJ Exercise limitation in chronic heart failure: central role of the periphery. J Am Coll Cardiol 1996;28:1092-102.

6. Massie BM, Conway M, Rajagopalan $B$, et al. Skeletal muscle metabolism during exercise under ischemic conditions in congestive heart failure: evidence for $a b$ normalities unrelated to blood flow. Circulation 1988;78:320-6.

7. Tang YD, Katz SD. Anemia in chronic heart failure: prevalence, etiology, clinical correlates, and treatment options. Circulation 2006;113:2454-61.

8. Dunn LL, Rahmanto YS, Richardson DR. Iron uptake and metabolism in the new millennium. Trends Cell Biol 2007; 17:93-100.

9. Fairbanks V, Beutler E. Iron deficiency. In: Beutler E, ed. Williams hematology. 6th ed. New York: McGraw-Hill, 2001:295304, 447-70.

10. Beard JL. Iron biology in immune function, muscle metabolism and neurona functioning. J Nutr 2001;131:Suppl 2: 568S-579S

11. Haas JD, Brownlie T IV. Iron deficiency and reduced work capacity: a critica review of the research to determine a causal relationship. J Nutr 2001;131:Suppl 2:676S-688S

12. Davies KJ, Maguire JJ, Brooks GA Dallman PR, Packer L. Muscle mitochondrial bioenergetics, oxygen supply, and work capacity during dietary iron deficiency and repletion. Am J Physiol 1982 242(6):E418-E427.

13. Satija P, Ondo WG. Restless legs syndrome: pathophysiology, diagnosis and treatment. CNS Drugs 2008;22:497-518.

14. Opasich C, Cazzola M, Scelsi L, et al. Blunted erythropoietin production and defective iron supply for erythropoiesis as major causes of anaemia in patients with chronic heart failure. Eur Heart J 2005 26:2232-7.

15. Nanas JN, Matsouka C, Karageorgopoulos D, et al. Etiology of anemia in patients with advanced heart failure. J Am Coll Cardiol 2006;48:2485-9.

16. Bolger AP, Bartlett FR, Penston HS, et al. Intravenous iron alone for the treatment of anemia in patients with chronic heart failure. J Am Coll Cardiol 2006;48: 1225-7.

17. Okonko DO, Grzeslo A, Witkowski T, et al. Effect of intravenous iron sucrose on exercise tolerance in anemic and nonanemic patients with symptomatic chronic heart failure and iron deficiency FERRIC-HF a randomized, controlled, observer-blind- ed trial. J Am Coll Cardiol 2008;51:10312

18. Toblli JE, Lombraña A, Duarte P, Di Gennaro F. Intravenous iron reduces NTpro-brain natriuretic peptide in anemic patients with chronic heart failure and renal insufficiency. J Am Coll Cardiol 2007;50:1657-65.

19. Usmanov RI, Zueva EB, Silverberg DS, Shaked M. Intravenous iron without erythropoietin for the treatment of iron deficiency anemia in patients with moderate to severe congestive heart failure and chronic kidney insufficiency. J Nephrol 2008;21:236-42.

20. Anker SD, Colet JC, Filippatos G, et al. Rationale and design of Ferinject Assessment in patient with IRon deficiency and chronic Heart Failure (FAIR-HF) study: a randomised, placebo controlled study of intravenous iron supplementation in patients with and without anaemia. Eur J Heart Fail 2009;11:1084-91.

21. Ganzoni AM. Intravenous iron-dextran: therapeutic and experimental possibilities. Schweiz Med Wochenschr 1970; 100:301-3. (In German.)

22. Green CP, Porter CB, Bresnahan DR, Spertus JA. Development and evaluation of the Kansas City Cardiomyopathy questionnaire: a new health status measure for heart failure. J Am Coll Cardiol 2000; 35:1245-55.

23. Rabin R, de Charro F. EQ-5D: a measure of health status from the EuroQol Group. Ann Med 2001;33:337-43.

24. McCullagh P. Regression models for ordinal data (with discussion). J R Stat Soc [B] 1980;42:109-42.

25. Benjamini Y, Hochberg Y. Controlling the false discovery rate: a practical and powerful approach to multiple testing. J R Stat Soc [B] 1995;57:289-300.

Copyright (C) 2009 Massachusetts Medical Society. 